\title{
SIMULATION MODELLING AS A TOOL FOR RISK ANALYSIS AND DEVELOPMENT OF STRATEGY TO INCREASE REAL ESTATE INCOME
}

\author{
Lesia Chubuk ${ }^{1}$
}

\begin{abstract}
The purpose of th article is to substantiate the possibility of applying methods for assessing the effectiveness and risks of investing for the analysis of income in the strategic management of real property. Methodology. The methodical bases of sensitivity analysis and simulation modeling of cash flows of real property income are stated. Results. The critical factors of costs and revenues affecting net present value of total cash flow from grain elevator real property object have been revealed. It is evidenced that the most significant factors influencing the amount of cash flows are the volume of sales of grain elevator services, to a lesser extent the total costs and the lack of sensitivity of net present value to staff salary variations. Simulation modeling of the change in net present value due to the change of the most significant uncertain factors was performed, which confirmed the assumptions about the efficiency of the investigated real property. The key factors are the main services that generate net operating income and critical expenses. Namely, services: storage, drying, shipment by road and rail, costs: fuel for drying, electricity, fuel for transportation of grain, staff salaries. For each factor, the relevant limits of change were established (determined by experts taking into account the average annual growth rate of the indicator) and cash flow simulation was performed. Practical implications. Statistical analysis of the model's behavior under the influence of random factors shows that the most probable value of the net present value of cash flows will be positive, despite the simulation of a significant change (+/-40\%) in electricity and fuel consumption factors for grain transportation. The values of the simple and discounted payback period also confirm the efficiency of the elevator property functioning. The indicator of the stability level demonstrate the need of planning input cash flows sources to cover the output cash flows. Value/originality. The expected profitability of grain elevator real property is largely determined by the factor of the volume of basic services sales (storage, drying, shipment and transport of products). This creates the preconditions for the subsequent assessment of the value of grain elevator real property based on the methodology of the income approach.
\end{abstract}

Key words: strategic real property income management, sensitivity analysis, simulation modeling method, cash flows, net operating income, net present value, grain elevator real property.

JEL Classification: L21, O22, E27

\section{Introduction}

Real estate is one of the main types of resources of the enterprise, occupying a significant part in their structure and acting as a consumer good, means of production, investment goods and financial assets. However, as studies of the evolution of concepts and the development of real estate management, real estate management only from the $90 \mathrm{~s}$ of the twentieth century began to be considered as part of strategic management. Strategic real estate management is subordinated to the general goal of ensuring the realization of business goals in the long run perspective the most efficient use of long-term real estate assets at minimal cost. The basis for the implementation of strategic management is a strategy as a set of long-term actions aimed at: establishing compliance between the characteristics of the property and the opportunities that determine its position in the market and in the real estate portfolio; maintaining competitive positions in the market; development (development) of real estate as a whole or its individual parts.

From the point of view of the real estate efficiency as the property, it is accepted that allocating kinds of management strategies focuses mainly on the following purposes:

\footnotetext{
Corresponding author:

${ }^{1}$ Taras Shevchenko National University of Kyiv, Ukraine.

E-mail: LChubuk@ukr.net

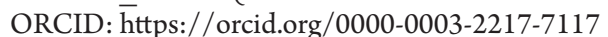


- increasing of capitalization and/or market value of the real estate object;

- maximizing the cash flow of income from the use of real estate in the short term, minimizing the cash flow of costs;

- ensuring a stable cash flow of income from the use of real estate for a long period of time;

- using of real estate for production or social purposes, removal of its useful properties.

The issues of increasing real property income, in particular, net cash flows and net operating income, along with reducing costs and maximizing value are of great practical importance in the process of strategic real property management.

At the time of managing real property, choosing investment alternatives, developing management strategies, there is a need to assess the effectiveness of real property investments and cash flows from real property, and therefore there are prerequisites for using methods of assessing efficiency and risk based on discounting techniques and dynamic investment analysis.

\section{Literature review}

Publications of some national scientists are devoted to the issue of strategic cost and profit management of enterprises (Prodanchuk, 2012; Skibenko \& Chimeris, 2011; Tyutyunnyk S. \& Tyutyunnyk Yu., 2016; Vlasenko \& Starodubtseva, 2018). However, these works focus mainly on the theoretical aspects of the study of strategic management of the enterprise as a whole, without detailing the management strategies of certain important types of assets and property of the enterprise, especially real property. Today in the scientific literature are almost not studied as highly specialized issues of application of risk analysis methods in assessing the effectiveness of grain elevator real property, however, they are of great practical importance. In practice, it is traditionally preferred to take into account the static indicators of efficiency assessment (profit after payment of interest and taxes, investment rate, specific investment income per unit of storage capacity, simple payback period). However, there is a need to use in the study of efficiency and in the development of management strategies indicators, based on the technique of discounting, supplementing such an assessment by risk analysis. First of all, the indicators of net present value of cash flows from real property and present value of net operating income are required to be more widely introduced in the field of grain elevator real property profitability analysis. These indicators are traditionally not only the basis for estimating the value by discounting, but are used to evaluate real options and build optimal strategies (Hitchner, 2006, pp. 1119, 1121; Pratt \& Niculita, 2008, pp. 516, 518-519; Manganelli, 2015, pp. 121-135, 137-188).
The purpose of the research material - demonstrate the possibilities and advantages of using methods to assess the effectiveness and analysis of investment risks, in particular, simulation modeling method to justify areas of increasing in real property income in strategic management.

\section{Methods}

The development of strategies to increase net cash flow and net operating income through the use of real property is based on identified factors and income growth potential through methods of assessing effectiveness and risks: sensitivity analysis, scenario analysis (or decision tree), simulation modeling method end so on.

\subsection{Sensitivity analysis method}

The method of sensitivity analysis is one of the basic methods of quantitative risk analysis, which consists in changing the values of critical parameters, substituting them into the financial model of the object and calculating the key performance indicators of the property at each change.

The sequence of sensitivity analysis in the general case is as follows (Savchuk, 2020, pp. 400-401; Dmitriev \& Koshechkin, 2001, pp. 28-29).

1. Selection of a key indicator of investment efficiency (most often - NPV).

2. The choice of factors in relation to which the developer of the investment project does not have the same judgment (i.e. is in a state of uncertainty). The following factors are typical: capital investments and working capital; market factors - the price of goods and sales; components of the cost of products, services; time of construction and commissioning of fixed assets, etc.

3. Establishment of nominal and limit (lower and upper) values of uncertain factors selected in the previous step of the procedure. There can be several limit values, for example, $+/-5 \%,+/-10 \%$ of the nominal value.

4. Calculation of the key indicator for all selected limit values of uncertain factors.

5. Plotting the sensitivity graph for all uncertain factors. This graph and/or the calculated coefficient of elasticity of the key performance indicator for each individual uncertain factor allows us to make inferences about the most critical factors that are affecting the operation of the facility. The aim is to pay the greatest attention to these factors in order to reduce risks. The advantages of the method are the clarity of the results, the possibility of implementation using software. The disadvantage is the separate analysis of the influence of factors on the key performance indicator, while in reality such influence is simultaneous. 


\subsection{Simulation modeling method}

Simulation modeling method (Monte Carlo method) is a procedure by which a mathematical model for determining a certain financial indicator (in particular, the net present value of cash flows from real property) is subjected to a number of simulations using a computer (Manganelli, 2015, pp. 160-162; Savchuk, 2020, pp. 402-404; Blank, 2003, pp. 291-292). The analysis process can be divided into the following stages (Figure 1).

During the simulation process, sequential scenarios are built using the original data, which are uncertain, based on the context of the situation, and therefore in the analysis they are taken as random variables. The simulation process is performed in such a way that the random selection of values from certain probability distributions does not violate the existence of known or assumed correlation relations among variables. The results of the simulation are summarized and analyzed statistically, in particular, in order to assess the degree of risk.

The first stage in the process of simulation is the creation of a predictive model. This model determines the mathematical relationships between numerical variables that relate to the forecast of the selected indicator. As a basic model for the analysis of the efficiency of real property use (income generation) will be used the model of cash flow and the calculation of net present value (NPV):

$$
N P V=\sum_{t=0}^{N} \frac{C F_{t}}{(1+i)^{t}},
$$

were $C F_{t}$ - net cash flow, the difference between input flows and output flows of real estate object (UAH);

$i$ - annual discount rate (units per unit);

$t$ - calculation period (years), $t=\overline{0 \ldots N}$.

In the simulation process, the values of the variables are chosen randomly within the specified ranges and in accordance with the probability distribution and correlation conditions. Generation of random numbers application packages are carried out according to a certain algorithm. The peculiarity of software data processing is that correlated random numbers are generated. For each set of such variables, the value of the performance indicator (use of the real property object) is calculated. All obtained values are stored for further statistical processing.

The final stage of risk analysis is the processing and interpretation of the results obtained at the stage of model calculations. Each individual calculation (experiment) is characterized by the probability of the event, which is equal to:

$$
\mathrm{p}=100 / \mathrm{n}
$$

where $\mathrm{p}-$ probability of single calculation (experiment);

$\mathrm{n}$ - sample size.

When modeling the net present value of cash flow from the use of real estate, it is advisable to use the

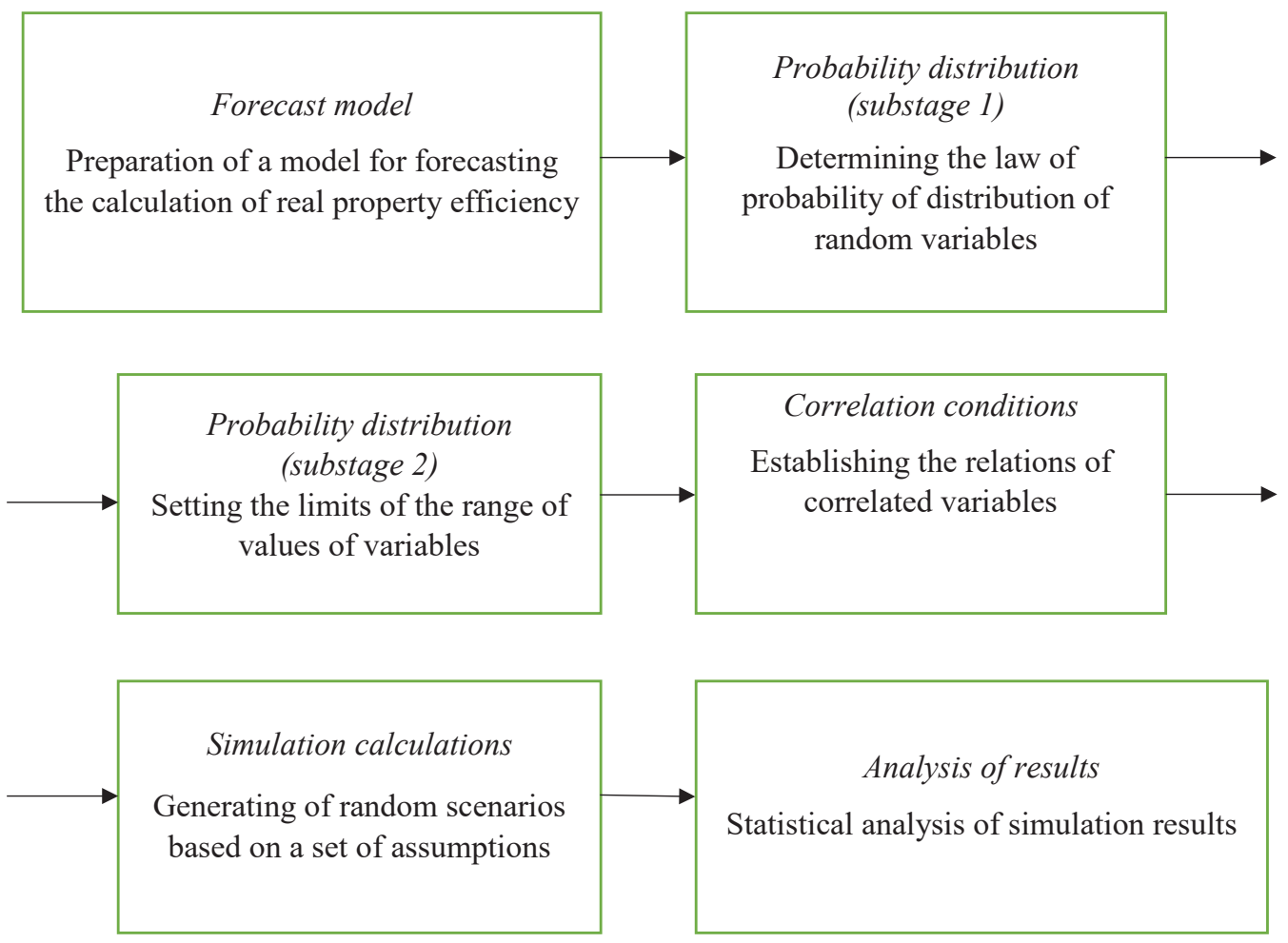

Figure 1. Stages of the process of simulation of real property efficiency

Sourse: compiled based on (Savchuk, 2020, p. 403; Blank, 2003, p. 292) 
probability of obtaining a negative value of NPV as a measure of risk. This probability is calculated based on statistical results of simulation as the product of the number of results with a negative value and the probability of a single calculation (experiment).

After performing several hundred calculations, a set of NPV values is obtained, for which the average value $(\mathrm{m})$ is calculated, as well as the risk indicator (standard deviation, d). According to the statistical rule of three sigma, the value of NPV should be in the following intervals:

- with a probability of $68,3 \%$ - in the range $(\overline{N P V}) \pm \mathrm{d}$;

- with a probability of $94,5 \%$ - in the range $(\overline{N P V}) \pm 2 \mathrm{~d}$;

- with a probability of $99,7 \%$ - in the range $(\overline{N P V}) \pm 3 \mathrm{~d}$.

\section{Results}

\subsection{Sensitivity analysis of the net present value of cash flows to income and expense factors}

The sensitivity analysis of the net present value of cash flows to changes in income and expense factors was performed on the basis of the cash flow model (formed by the equity scheme) from income and expenses of rain elevator real property of "Zernokompleks "Sivash" LLC (Kozyatyn, Vinnytsia region). This company is part of the association of "Tessla Group" companies («Tesslagroupe». Kompanii, 2020). Elevator real estate has significant features in valuation, as these objects are simultaneously operating business, integral property complexes and it is impossible to separate real property cash flows from business cash flows for such objects (except in the case of renting). In the formation of the model of total cash flow from all activities, the data of the operational reporting of the enterprise for the five-year period (from 2015-2016 marketing year to 2019-2020) and the forecast for 2020-2021 were used. For reference, the main characteristics of the studied elevator property are as follows: fair value (property purchased in 2010) - \$3.2 million (UAH 25.92 million), capacity is 53 thousand tons, annual turnover for 2015-2016 is 60 thousand tons (1.13 times per year), there are significant costs for equipment and repairs during 2015-2018, which were associated with the construction of a warehouse with a capacity of 8 thousand tons of grain.
According to the initial data on the construction of cash flows from the grain elevator property (for years 2015-2021), a sensitivity analysis of income and expense factors for the retrospective and forecast period as a whole was done using Project Expert software. The actual values of tax rates (income tax, value added tax, single social contribution) were used for calculations. The discount rate was chosen as $16 \%$, which corresponds to the level of the average market deposit rate on longterm deposits for businesses for the year of the study (2015) according to the National Bank of Ukraine.

The results of the sensitivity analysis demonstrates in Table 1-2. The volume of sales of services (sales price), general expenses, staff salaries and tax rates were chosen as uncertain factors for sensitivity analysis in the model.

Calculations shows that the volume of sales of grain elevator real property services is the most significant factor influencing the amount of cash flows. Reducing sales by $30 \%$ from the regulatory (baseline) level causes a negative value of cash flow at constant fixed costs and becomes critical for the efficiency of the grain elevator property. Based on the value of the coefficient of elasticity of NPV on income, an income reduction by $1 \%$ causes a decrease in the present value of cash flows by approximately $3.88 \%$.

When determining income targets for certain types of grain elevator real property services and total income, it is advisable to establish a specific relationship between the change in income and the present value of cash flows to develop a strategy. Thus, the prognostic function of real property management can be implemented.

Total costs as an uncertain factor taking into account the entire period of the initial data of the model shows a smaller degree of influence on the resulting present value of cash flows (for comparison: the coefficient of elasticity NPV to change costs in the analysis of cash flows only the first marketing year (2016-2016) is 14.21). According to the results of the calculation, the critical from the standpoint of loss of efficiency is the growth of total costs by $40 \%$ or more. The factor of salary loses priority according to the degree of influence; the coefficient of elasticity behind it becomes less than one, which indicates the insensitivity of net present cash flow to changes in salary. The factor of change in

Table 1

Change in the net present value of cash flows of the grain elevator property in 2015-2021 depending on changes in income and expense factors from 0 to $-50 \%$

\begin{tabular}{|l|c|c|c|c|c|c|}
\hline \multirow{2}{*}{$\begin{array}{c}\text { Income/ expense } \\
\text { factor }\end{array}$} & $-50 \%$ & $-40 \%$ & $-30 \%$ & $-20 \%$ & $-10 \%$ & $0 \%$ \\
\cline { 2 - 7 } & -17767214 & -10020531 & -2871825 & 3874512 & 10352716 & 16811541 \\
\hline Sales volume & 35029985 & 31421075 & 27806195 & 24189519 & 20552376 & 16811541 \\
\hline General expenses & 21274879 & 20392810 & 19509868 & 18619797 & 17719112 & 16811541 \\
\hline Staff salary & 21606502 & 20570048 & 19574134 & 18616529 & 17696083 & 16811541 \\
\hline Tax rates & &
\end{tabular}

Source: calculation according to the company LLC "Zernokompleks "Sivash" data (association of enterprises "Tessla Group") 
Table 2

Change in the net present value of cash flows of the grain elevator property in 2015-2021 depending on changes in income and expense factors from 0 to $+50 \%$

\begin{tabular}{|l|c|c|c|c|c|c|}
\hline \multirow{2}{*}{$\begin{array}{c}\text { Income/ expense } \\
\text { factor }\end{array}$} & $+10 \%$ & $+20 \%$ & $+30 \%$ & $+40 \%$ & $+50 \%$ & $\begin{array}{c}\text { Coefficient of } \\
\text { elasticity (NPV / } \\
\text { Factor of income } \\
\text { (expenses) }\end{array}$ \\
\hline Sales volume & 23044678 & 29154287 & 35254339 & 41353402 & 47451949 & 3,88 \\
\hline General expenses & 12902051 & 8982783 & 5001201 & 982155 & -3116574 & 2,27 \\
\hline Staff salary & 15893249 & 14966356 & 14040082 & 13114912 & 12191968 & 0,54 \\
\hline Tax rates & 15961174 & 15135309 & 14337151 & 13569536 & 12829752 & 0,52 \\
\hline
\end{tabular}

Source: calculation according to the company LLC "Zernokompleks "Sivash" data (association of enterprises "Tessla Group")

tax rates demonstrates the lack of significant impact on net present value.

Given the shortcomings of the method of sensitivity analysis (separation of the influence of factors on the resulting indicator), it should be considered only as a preliminary step in the study of income to develop a management strategy. To ensure the complexity of the study, changes in the profitability factors of a real property object should be considered in connection with changes in other uncertain factors, primarily costs, using the methods of scenario analysis, decision tree and simulation modeling method.

In the case when accurate estimates of risk parameters (as in the methods of scenario analysis or decision tree (probability tree)) cannot be set, and only the intervals of probable fluctuations of cash flow can be determined by experts, it is advisable to use the simulation modeling method (Monte Carlo method).

\subsection{Simulation modeling of cash flows under the influence of changes in key factors of incomes and costs}

To analyze the efficiency of the operation of elevator real property and to study the critical factors of income, simulation modeling method based on cash flows for the period 2015-2021 was used. Instead of unambiguous values of operating parameters, uncertainty intervals were set, based on the assumption of a uniform probability distribution on each of the intervals. According to the central limit theorem of probability theory, if the sample is large enough, then under certain, fairly common conditions, the sum of a set of random variables will follow the normal distribution regardless of the type of distribution of each individual random variable. Based on the default normal distribution in the software product Project Expert, the simulation of key factors was carried out and taking into account the obtained values, the indicators of economic efficiency were calculated. The key factors of calculation are the main services that form the net operating income and critical total costs, namely: the volume of grain storage services; volume of grain drying services; the volume of shipment services for road transport; the volume of shipment services for railway transport; fuel costs for drying; electricity costs; land lease costs; fuel costs for grain transportation; staff salaries.

For each factor in the software product Project Expert using the simulation module "Monte Carlo" the corresponding limits of change were set (determined by experts taking into account the average annual growth rate) (Table 3 ).

The results of simulation modeling (series of 500 calculations) are given in Table 4. The discount rate for calculations was chosen at the level of $16 \%$.

Statistical analysis of the model's behavior under the influence of random factors shows that the most

Table 3

Limits of change in key factors for simulating modeling cash flows from a grain elevator property

\begin{tabular}{|c|l|c|c|}
\hline № & \multicolumn{1}{|c|}{ Factor } & Deviation, $-\%$ & Deviation, $+\%$ \\
\hline 1 & \multicolumn{1}{|c|}{2} & 3 & 4 \\
\hline 1 & The volume of grain storage services & -20 & +20 \\
\hline 2 & The volume of grain drying services & -10 & +10 \\
\hline 3 & The volume of grain shipment services for road transport & -20 & +20 \\
\hline 4 & The volume of grain shipment services for railway transport & -20 & +20 \\
\hline 5 & Fuel costs for drying & -40 & +40 \\
\hline 6 & Electricity costs & -40 & +40 \\
\hline 7 & The cost of renting land & -30 & +30 \\
\hline 8 & Fuel costs for transportation & -30 & +30 \\
\hline 9 & Salary & -30 & \\
\hline
\end{tabular}

Source: complete by the author 
Table 4

Indicators of efficiency and risks of operation of the grain elevator real property object in 2015-2022

\begin{tabular}{|c|l|c|c|}
\hline № & \multicolumn{1}{|c|}{ Indicators of efficiency } & Average value & Uncertainty (coefficient of variation) \\
\hline 1 & Discounted payback period, months & 28 & 0,28 \\
\hline 2 & Profitability index & 4,43 & 0,17 \\
\hline 3 & Net present value of cash flows, UAH & 16787479 & 0,14 \\
\hline 4 & Internal rate of return, \% & 119,82 & 0,22 \\
\hline 5 & Simple payback period, months & 24 & 0,32 \\
\hline 6 & Average rate of return (accounting) & 124,01 & 0,17 \\
\hline 7 & Modified internal rate of return, $\%$ & 48,05 & 0,09 \\
\hline
\end{tabular}

Source: calculation according to the company LLC "Zernokompleks "Sivash" data (association of enterprises "Tessla Group")

probable value of the net present value (NPV) of cash flows of real estate will fluctuate around the value $(\overline{N P V})=16787479(\mathrm{UAH})$. According to the rule of three sigma, with a probability of $99.7 \%$, the value of NPV will fit in the range $(\overline{N P V}) \pm 3 \mathrm{~d}$, even the lower limit of which will be positive (9,737 thousand 23,838 thousand UAH). The distribution of NPV (95\% confidence interval) is illustrated in Figer 2. In all 500 experiments, the value of the indicator is positive, and the uncertainty is $14 \%$, which corresponds to a low level of risk (up to $20 \%$ ).

\section{Discussion}

It should be noted that in this study, the increase in the number of simulations of NPV change (from 100 to 500) led to the approximation of the expected value to the value of NPV, obtained by the basic formula without taking into account the probability of risk. This can be interpreted as confirming the stability of the efficiency of a particular property. However, it is not obvious that in all cases more simulations are better in terms of improving the quality of the simulation results.
The choice of the optimal number of experiments in modeling is at the discretion of the researcher.

When setting quantitative goals for the strategy of increasing income from elevator real estate, it is advisable to focus on the identified relationship between the increase in sales and changes in net present value of cash flows. A $1 \%$ increase in revenues from any of the basic services or a combination of them will cause an increase in NPV by $3.88 \%$, which as a result of direct capitalization is equivalent to an increase in property value by $24.25 \%$ (at a capitalization rate of $16 \%)$. The latter conclusion indicates the possibility of applying sensitivity analysis and simulation modeling in value-based management. Thus, the scope of application of simulation modeling in economic research is wider than has been mostly stated so far (Wu \&Olson, 2013).

The author identifies the following difficulties in the practical application of the simulation method (Monte Carlo method) for risk analysis and efficiency of real estate:

- complexity of collecting factual data to model for calculation of the performance indicators;

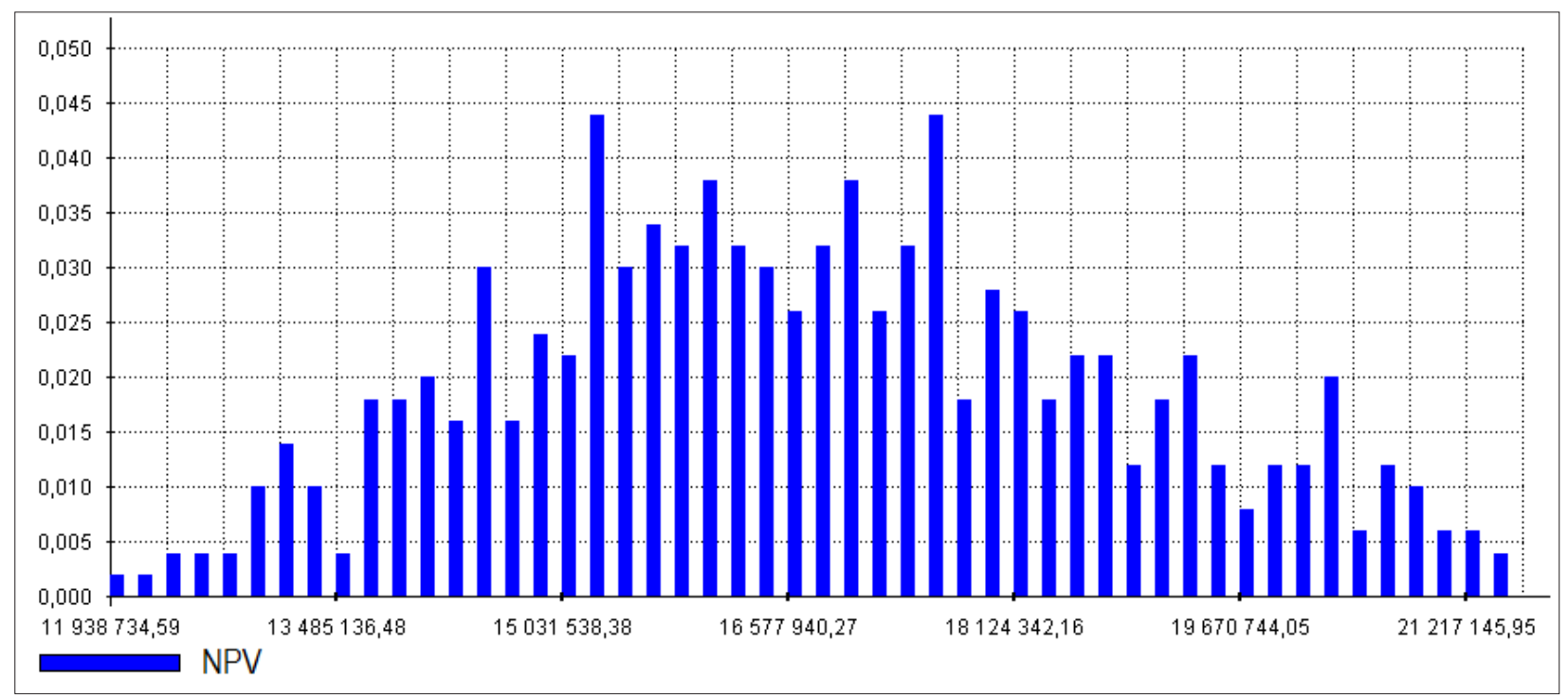

Figure 2. NPV distribution of the grain elevator real estate cash flow

Source: Simulation modelling (Monte Carlo method) in Project Expert 
- problem of correlation of variables, which can lead to incorrect conclusions;

- accuracy of the result depends on the number of experiments performed ("runs" of the model), but their optimal number is unknown;

- complexity of detection, breadth of the list of key risk factors and choice of limits of their changes.

\section{Conclusions}

The operation of grain elevator real property in the studied model is generally efficient and characterized by a low degree of risk, because with a high probability NPV cash flow is positive, despite the imitation of a significant change in electricity and fuel consumption factors for grain transportation. The expected profitability is largely determined by the sales price factor (sales volume) of basic services - storage, drying and shipment by road and railway transport. The high value of the internal rate of return can be explained in particular by the fact that the cash flow model was built as cash flow to equity (excluding the financial cost of paying interest on loans). Simple and discounted payback periods also confirm the efficiency of operation of the researched object of grain elevator real property. The discounted payback period of investments in construction and purchase of equipment is 2.33 years, and the coefficient of variation on this indicator is within $30 \%$, which indicates a generally acceptable level of risk.
Among the indicators of the model, which allow to diagnose problematic aspects of the operation of the object and the formation of cash flows - an indicator of the level of stability, which in this case is $0 \%$. This indicator shows the share of calculations of their total number (as a percentage), which would not cause a shortage of cash and desynchronization of cash flows. Thus, randomly generated real estate cash flows in all cases require planning to cover cash outflows with sources of cash inflows.

The main measures that allows increasing the profitability of grain elevator real estate in strategic management are follows: raise the turnover of storage tanks, in particular by increasing the speed of shipment to transport; reduction in the cost of transportation; growth in sales volume of services (tariff increases, development of loyalty programs for customers).

Therefore, the use of methods for assessing the effectiveness and risks of investing in real estate based on the technique of discounting, in particular, sensitivity analysis and simulation modeling method is convenient and clear from an analytical point of view to develop a strategy for real estate income management.

Another positive aspect of using the simulation modeling method for the analysis of income from the operation of real property, the development of strategies to maximize them is the ability to assess the effectiveness (risks) at the stage of construction or acquisition of real property.

\section{References:}

Prodanchuk, M. A. (2012). Strategic cost management of agricultural enterprises. Oblik $i$ finansy APK: bukhhalterskyi portal. Available at: http://magazine.faaf.org.ua/ekonomika-pidpriemstv.html (accessed 2 February 2020). (in Ukrainian)

Skybenko, S. T., \& Chymerys, V. M. (2011). Formation of profit management strategy of the enterprise. Naukovyi visnyk Poltavskoho universytetu ekonomiky i torhivli, vol. 6(51), part 2, pp. 153-154. (in Ukrainian)

Tiutiunnyk, S. V., \& Tiutiunnyk, Yu. M. (2016). Mechanisms of factor analysis of indicators of financial condition of branches of economy. Aktualni problemy ekonomiky, vol. 5, pp. 421-429. (in Ukrainian)

Vlasenko, T. O., \& Starodubtseva, O. S. (2018). Profitability of the enterprise: the essence and efficiency of management. Molodyi vchenyi, vol. 12(64), pp. 256-258. (in Ukrainian)

Hitchner, J. R. (2006). Finance Valuation. Applications and Models. 2nd edition. John Wiley\&Sons, Inc.

Pratt, S. P., \& Niculita, A. V. (2008). The Analysis and Appraisal of Closely Held Companies. 5th Edition. McGraw-Hill.

Manganelli, B. (2015). Real Estate Investing: Market Analysis, Valuation Techniques, and Risk Management. Springer.

Savchuk, V. P. (2020). Enterprise financial management / derivative electronic edition based on a printed analogue (4th edition). Moscow: BINOM. Laboratoriya znaniy. (in Russian)

Dmitriev, M. N., \& Koshechkin, S. A. (2001). Methods for quantitative analysis of the risks of investment projects. Ekonomika stroitelstva, vol. 5, pp. 27-34. (in Russian).

Blank, I. A. (2003). Enterprise Investment Management. Kiev: Nika-Tsentr, Elga-N. (in Russian)

«Tesslagroupe». Kompanii (2020). Elevatirist.som. Available at: https://elevatorist.com/kompanii/253--gktesslagroup (accessed 2 May 2020). (in Russian)

Wu, D. D., \& Olson, D. L. (2013, November). Computational simulation and risk analysis: An introduction of state of the art research. Mathematical and Computer Modelling, vol. 58, 9-10, pp. 1581-1587. 